\title{
Impact of an educational intervention using the 20/20/20 rule on Computer Vision Syndrome
}

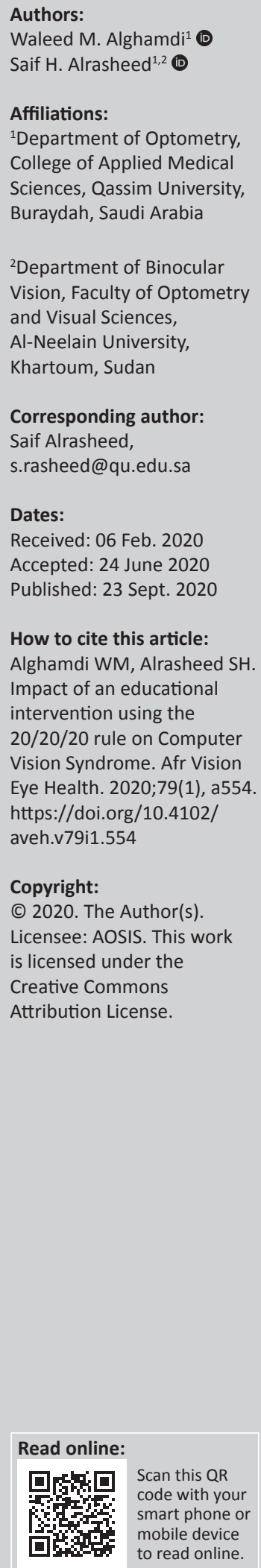

Background: Global estimates suggest that nearly 60 million people suffer from Computer Vision Syndrome (CVS).

Aim: The goal of this research was to evaluate the effectiveness of an educational intervention using the 20/20/20 rule to reduce CVS symptoms.

Setting: The study was conducted in the Qassim University eye clinic.

Methods: An experiential intervention study was conducted amongst 40 patients with CVS, with their age ranging from 21 to 38 years. The sample was divided into two groups: (1) intervention patients $(n=20)$, who were given a structured advice booklet about how to reduce CVS symptoms using the 20/20/20 rule, and (2) control $(n=20)$ with CVS, who were given advice to simply drink more water. Both groups completed two questionnaires, namely, the CVS-Q and Dry Eye Questionnaire-5 (DEQ-5). Dry eye clinical tests were performed. The same procedures were repeated after 20 days to compare the outcomes before and after intervention.

Results: The study findings revealed that patients complaining from dry eye symptoms showed significant changes after the educational intervention (pre-intervention: $9.05 \pm 4.32$; post-intervention: $7.10 \pm 3.61)(p=0.04)$. The symptoms of CVS were slightly reduced after educational intervention, from $9.00 \pm 3.03$ to $8.35 \pm 1.89(p=0.38)$. However, TBUT showed a significant increase after the educational intervention (pre-intervention: $6.20 \pm 2.02$ s; postintervention: $8.55 \pm 2.84 \mathrm{~s})(p=0.005)$.

Conclusion: The educational intervention of the 20/20/20 rule induces significant changes in dry eye symptoms and tear film and some limited changes for ocular surface integrity.

Keywords: Computer Vision Syndrome; dry eye; ocular surface integrity; 20/20/20 rule; Dry Eye Questionnaire; tear film break-up time; digital eye strain; ocular discomfort.

\section{Introduction}

Computer vision syndrome (CVS), also referred to as digital eye strain, is a growing public health issue, with global estimates suggesting that nearly 60 million people suffer from it. ${ }^{1,2}$ This is mainly a result of the amount of time spent behind digital screens, which has increased dramatically in the past few decades. ${ }^{3}$ In addition, CVS is believed to reduce work productivity, increase the error rate, affect job satisfaction and impair visual ability. ${ }^{1,2}$ Almost $90 \%$ of computer users may experience visual and ocular symptoms such as headaches, eye strain, ocular discomfort, dry eye, diplopia and blurred vision. ${ }^{4,5}$

The American Optometric Association defines CVS as a combination of eye and vision problems associated with the use of computers. These symptoms result from the individual having insufficient visual capabilities to perform the computer task comfortably. A review of published articles over the last 65 years reported that symptoms of CVS were classified into internal ocular symptoms (eye strain and headache), external ocular symptoms (irritation, dryness and burning), visual symptoms (blur, double vision) and musculoskeletal symptoms (neck and shoulder pain). ${ }^{3}$ The prevalence of visual symptoms resulting from CVS was higher amongst subjects who spent more than $4 \mathrm{~h}$ working on video display terminals (VDTs). ${ }^{6}$ Smita et al. reported that almost $62 \%$ of individuals who use computers for more than $6 \mathrm{~h}$ daily have CVS symptoms. ${ }^{7}$ Studies ${ }^{5,8,9}$ have revealed that the symptoms of CVS are more prevalent amongst spectacle and contact lens wearers.

Several researchers ${ }^{9,10,11,12,13}$ have reported that the distance of the computer from the eyes is a risk factor for CVS and that the closer computers are to the eyes, the more accommodation and accommodative convergence must change to achieve clear retinal images. The physiological explanation for the challenge to accommodation and accommodative convergence is that near 
distance results in excess accommodation, which leads to overworking the ciliary muscles of the eye, which is manifested as eye fatigue and headache. Prolonged use of computers tends to reduce the rate of blinking, which can cause redness, dryness and eye strain.

Although there is no consensus on how to manage CVS, a number of recommendations have been widely adopted. These include a combination of adjustment of the work station and lighting, antiglare filters, using a suitable distance for the computer monitor and regular work breaks, all of which may help in relieving the symptoms. ${ }^{14}$ In addition, the 20/20/20 rule usually is given as advice by eye care professionals to their patients experiencing near-point visual strain or prolonged exposure to near-point devices. ${ }^{15}$ The rule can be stated as follows: every $20 \mathrm{~min}$, take a $20 \mathrm{~s}$ break and focus your eyes on something at least 20 feet away. ${ }^{16}$ Boulet reported that this $20 / 20 / 20$ rule is commonly found on the websites of optometric associations, although it has very little evidentiary support, and its therapeutic benefits are unclear. ${ }^{15}$ However, all of these educational or environmental methods to reduce CVS are of unknown efficiency. Therefore, the aim of this study was to evaluate whether educational intervention with the 20/20/20 rule is effective to reduce CVS symptoms and the associated dry eye signs and symptoms.

\section{Methods Study design}

This was an experimental intervention study, conducted amongst participants at an optometry clinic. The study included 40 participants suffering from CVS whose ages ranged from 21 to 38 years, and they were assigned randomly to two equal groups (20 participants were assigned to the intervention group and 20 participants to the control group).

\section{Inclusion criteria}

All participants were aged from 21 to 38 years, used digital devices at least $4 \mathrm{~h} /$ day and scored $\geq 6$ in the CVS questionnaire as used. The participants were also required to be nearemmetropes with no ocular or systemic clinical findings or use of medications that may cause dry eye. Emmetropia was defined as a refractive error between -0.75 dioptres (D) and $0.75 \mathrm{D}$ spherical equivalent. Cylinder less than 0.25 D. Participants who had undergone corneal refractive surgery or who were previous or current rigid gas permeable (RGP) or soft contact lens wearers were excluded from the study. The reason for including only younger participants in this study was to avoid age-related confounding effects that could include dry eye and presbyopia.

\section{Study procedures}

This study was approved by the Ethics Committee of the Qassim Health Office and was conducted according to the Declaration of Helsinki guidelines. Participants attended two visits, and all gave written informed consent after having the procedures of the study explained to them.

\section{Baseline visit (Visit 1)}

At the first visit, medical and ocular histories, CVS questionnaires, visual acuities and objective refractions were obtained to identify those participants who met the study criteria.

Symptoms: All participants were required to complete the Computer Vision Syndrome Questionnaire (CVS-Q), which was designed to measure visual symptoms related to exposure to computers in the workplace. The CVS-Q consists of questions relating to 16 symptoms of CVS that are scored using two rating scales: one for frequency and the other for intensity. In a previous study, the CSV-Q had acceptable sensitivity and specificity over $70 \% .{ }^{17}$ Those scoring $\geq 6$ were considered as individuals suffering from CVS and were included in this study.

Then, each participant completed the Dry Eye Questionnaire 5 (DEQ-5), which has been considered a valid instrument for the assessment and diagnosis of dry eye amongst a population. ${ }^{18,19}$ This questionnaire consists of five questions and is self-administered to evaluate the frequency and intensity of eye discomfort and dryness, as well as the frequency of eye tearing. ${ }^{18}$

Clinical evaluation for dry eye disease: Tear meniscus height $(\mathrm{TMH})$ was measured to evaluate the tear quality and was assessed by slit lamp biomicroscopy. ${ }^{20}$ The tear break-up time (TBUT) test was performed to evaluate the stability of the tear film using a fluorescence strip in each patient; TBUT was calculated as the time between the last blink (third one) and the appearance of the first dry spot in the examination.

Ocular surface and eyelid integrity: The status of the cornea and conjunctiva were evaluated with fluorescein, using a slitlamp biomicroscope with cobalt blue light and a Wratten filter, and graded using the Efron $0-4$ grading scale. The levels of conjunctival bulbar and limbal redness as well as palpebral redness and roughness were observed with the biomicroscope (white light) and graded, where 0 indicated very slight and 4 was severe.

\section{Intervention}

The intervention group $(n=20)$ were educated about CVS and given a structured advice booklet about how to reduce CVS and related symptoms using the 20/20/20 rule (every $20 \mathrm{~min}$, take a $20 \mathrm{~s}$ break and focus your eyes on something at least 20 feet away). In addition, a sticker was fixed on each computer monitor to remind users of the $20 / 20 / 20$ rule and to blink more often. For the control group, which also included 20 participants, only advice to drink more water was suggested.

\section{Follow-up visit (Visit 2)}

Twenty days after the baseline visit, all participants attended the follow-up visit $(N=40)$ to investigate the impact of 
the 20/20/20 educational intervention as compared to the control. All procedures were repeated as explained above from least invasive to most invasive: the CVS-Q, DEQ-5, blink rate, tear film evaluation and, finally, ocular surface and eyelid integrity.

\section{Data analysis}

All statistical analyses were performed using the Statistical Package for the Social Sciences (SPSS) software package version 22.0 (SPSS, Inc., Chicago, IL, United States). Paired $t$-tests were used for the between-visit comparisons for normally distributed data and Wilcoxon tests were used for ordinal data, with $p<0.05$ considered as statistically significant in this study.

\section{Ethical considerations}

This study was approved by the Human Research Ethics Committee of the Qassim Health Office (ethical clearance number: 1441-1165872, $3 \backslash 2 \backslash 2019)$ and was conducted according to the Declaration of Helsinki guidelines. The participants attended two visits, and all gave written informed consent after having the procedures of the study explained to them.

\section{Results}

\section{Demographic characteristics of participants}

The study included 40 participants with CVS; all of them were men, and their ages ranged from 21 to 38 years, with a mean and standard deviation (s.d.) of $28.3 \pm 5.8$ years. The intervention group included 20 patients, with a mean and s.d. for age of $28.4 \pm 6.4$ years. The control group included 20 patients, with mean age \pm s.d. of $27.3 \pm 5.4$ years. There was no significant difference in mean age between the intervention and control groups (independent $t$-test, $p=0.94$ ).

\section{Computer Vision Syndrome Questionnaire and Dry Eye Questionnaire 5 results}

As shown in Table 1, there were no significant changes in CVS scores between visits in either intervention $(p=0.38)$ or control group ( $p=0.42$ ) (Figures 1 and 2$)$. However, symptoms measured by the DEQ-5 showed significant reductions between visits in the intervention group $(p=0.04)$, whereas no significant changes were found between visits in the control group ( $p=0.28$ ) (Figures 3 and 4 ).

\section{Tear film and clinical findings of dry eye}

There was no difference between visits in TMH measurements and blink rate in both the intervention (paired $t$-tests, $p=0.28$ ) and control $(p=0.29)$ groups. In the intervention group (Figure 5 and Table 2), TBUT measurements were significantly higher in the follow-up visit (mean \pm s.d.: $8.55 \pm 2.83 \mathrm{~s}$ ) compared to the baseline measurements $(6.20 \pm 2.02 \mathrm{~s}, p=$ 0.005). The TBUT levels were not significantly changed between visits in the control group ( $p=0.27$ ) (see Figure 6).
TABLE 1: Group means and standard deviations for Computer Vision Syndrome Questionnaire and Dry Eye Questionnaire 5 for baseline and follow-up visits for both intervention and control groups with the outcomes of paired $t$-test intergroup comparisons.

\begin{tabular}{lllcc}
\hline Test & Group & Visits & Mean \pm s.d. & $p$ \\
\hline CVS & Intervention & Baseline & $9.00 \pm 3.03$ & 0.38 \\
& & Follow-up & $8.35 \pm 1.89$ & \\
& \multirow{2}{*}{ Control } & Baseline & $8.05 \pm 1.47$ & 0.42 \\
& & Follow-up & $7.55 \pm 2.54$ & \\
DEQ-5 & Intervention & Baseline & $9.05 \pm 4.32$ & 0.04 \\
& & Follow-up & $7.10 \pm 3.61$ & \\
& \multirow{2}{*}{ Control } & Baseline & $9.15 \pm 2.05$ & 0.28 \\
& & Follow-up & $9.70 \pm 2.43$ & \\
\hline
\end{tabular}

Note: Quantities are unit-less here.

CVS, computer vision syndrome; DEQ-5, dry eye questionnaire 5; s.d., standard deviation.

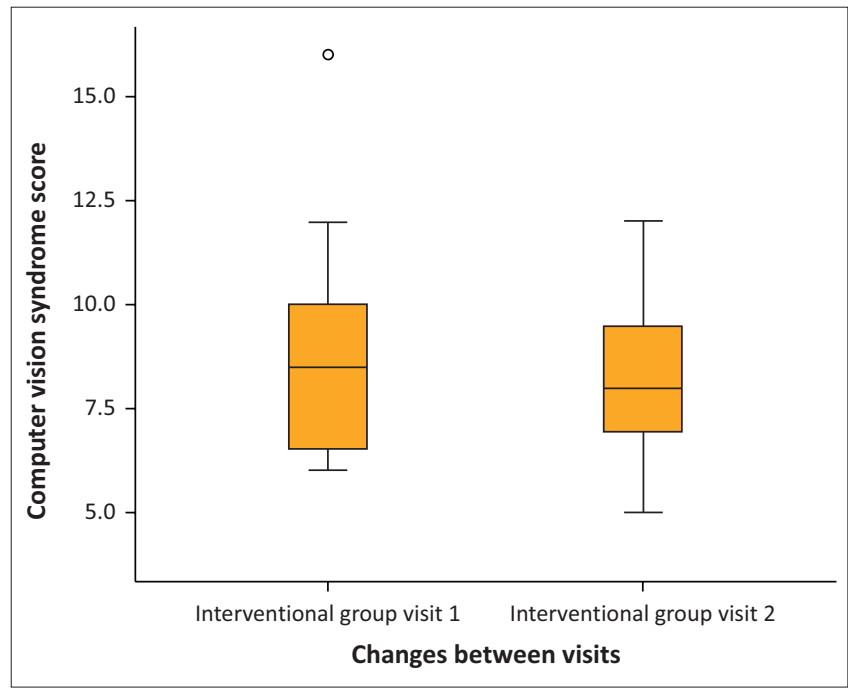

FIGURE 1: Box plots for Computer Vision Syndrome questionnaire score for the intervention group. No significant changes between visits.

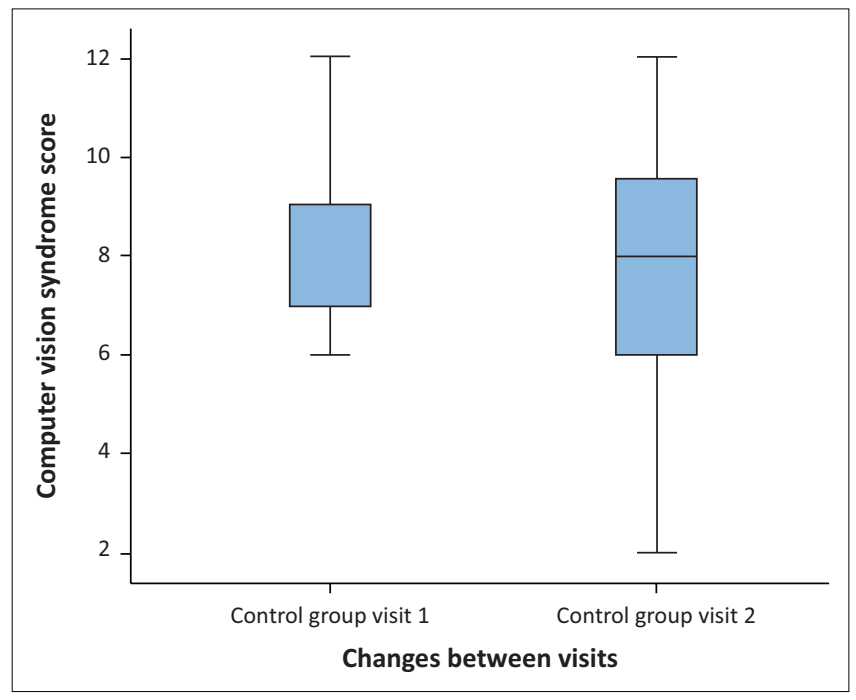

FIGURE 2: Box plots for Computer Vision Syndrome questionnaire score for the control group. No significant changes between visits.

\section{Ocular surface integrity}

Table 3 shows the results of different variables of ocular surface integrity. There was no difference between visits in either group in the scores of bulbar redness, palpebral redness and roughness, meibomian gland dysfunction (MGD) or 


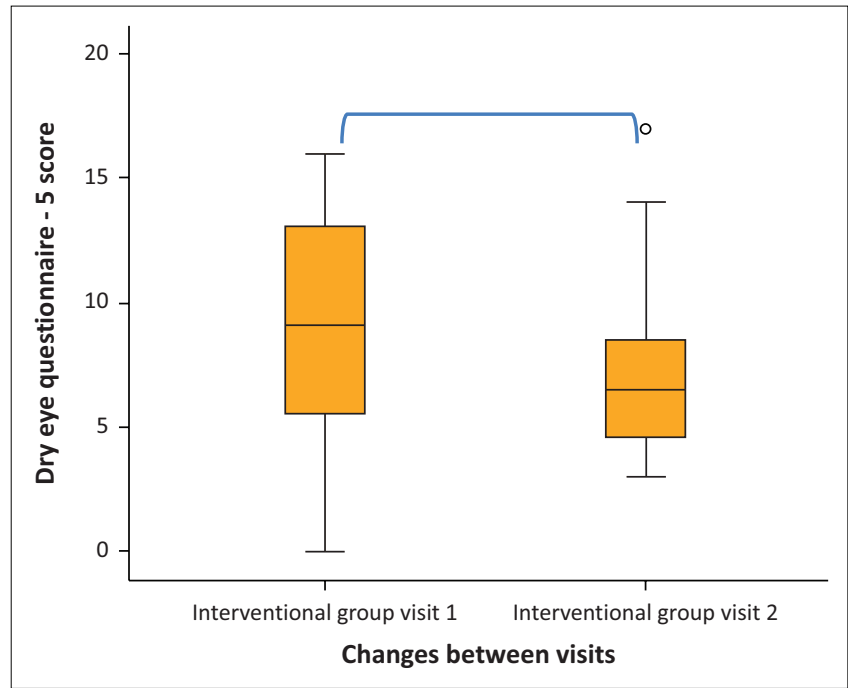

FIGURE 3: Box plots for Dry Eye questionnaire 5 score for the intervention group. Significant changes between visits.



FIGURE 4: Box plots for Dry Eye questionnaire 5 score for the intervention group. No significant changes between visits.

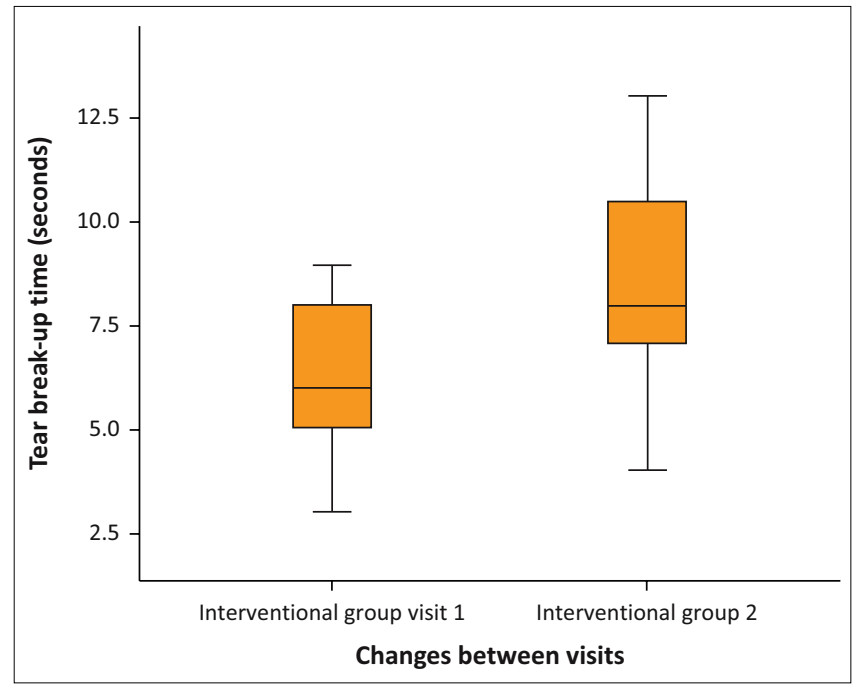

FIGURE 5: Box plots for tear film break-up time measurements for the intervention group. Significant changes between visits. corneal staining. In the intervention group, the limbal redness score was significantly lower at the follow-up visit $(1.8 \pm 0.61)$ compared to the baseline visit $(2.4 \pm 0.99 ; p=0.04)$, whereas no significant changes were found in the control group.

\section{Discussion}

One of the major effects of the technology revolution is the increase in use of smart digital devices in all aspects of life. Despite the remarkable advantages, the use of computers and other visual display terminals for a prolonged time may have negative effects on vision and the ocular surface, leading to the development of CVS., ${ }^{421}$ The current study assessed whether an educational intervention with the $20 / 20 / 20$ rule would be effective to reduce CVS symptoms and the associated dry eye signs and symptoms amongst participants. The study revealed that the educational intervention induces significant changes in dry eye symptoms $(p=0.045)$. This is in line with the American Optometric Association, which suggests that following the $20 / 20 / 20$ rule in daily near activities could eliminate the symptoms of CVS. ${ }^{22}$ However, there were no significant changes in the CVS scores between visits in the intervention

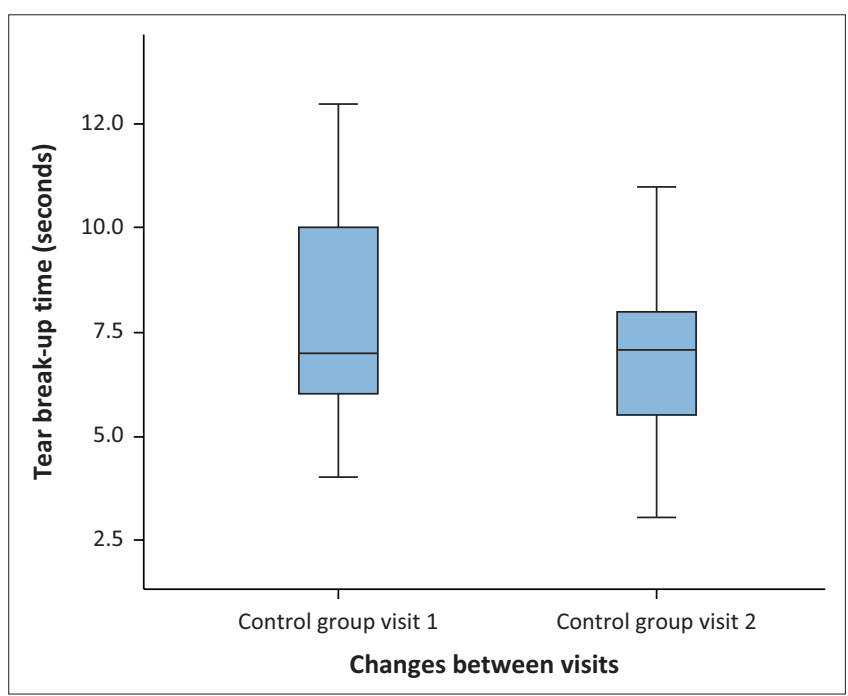

FIGURE 6: Box plots for tear film break-up time measurements for the control group. No significant changes between visits.

TABLE 2: Group means and standard deviations for clinical variables for baseline and follow-up visits for both intervention and control groups, for each indicated variable, with the outcomes of paired $t$-test intergroup comparisons.

\begin{tabular}{lllcc}
\hline Test & Group & Visit & Mean \pm s.d. & $p$ \\
\hline Tear meniscus & Intervention & Baseline & $0.32 \mathrm{~mm} \pm 0.10 \mathrm{~mm}$ & 0.28 \\
& & Follow-up & $0.30 \mathrm{~mm} \pm 0.23 \mathrm{~mm}$ & \\
& Control & Baseline & $0.30 \mathrm{~mm} \pm 0.11 \mathrm{~mm}$ & 0.30 \\
& & Follow-up & $0.22 \mathrm{~mm} \pm 0.24 \mathrm{~mm}$ & \\
& Intervention & Baseline & $6.20 \mathrm{~s} \pm 2.02 \mathrm{~s}$ & 0.005 \\
& & Follow-up & $8.55 \mathrm{~s} \pm 2.84 \mathrm{~s}$ & \\
Tear film & Break-up time & Baseline & $7.80 \mathrm{~s} \pm 6.5 \mathrm{~s}$ & 0.27 \\
& \multirow{2}{*}{ Control } & Follow-up & $6.85 \mathrm{~s} \pm 5.8 \mathrm{~s}$ & \\
& Intervention & Baseline & $9.15 \pm 5.82$ & 0.30 \\
& & Follow-up & $11.40 \pm 6.25$ & \\
Blink rate & Control & Baseline & $10.6 \pm 5.49$ & 0.95 \\
& & Follow-up & $10.55 \pm 7.63$ & \\
\hline
\end{tabular}

s.d., standard deviation. 
TABLE 3: Group means and standard deviations for clinical variables graded with the Efron scale for baseline and follow-up visits for both the intervention and control groups, together with Wilcoxon paired-test intergroup comparisons.

\begin{tabular}{|c|c|c|c|c|}
\hline Test & Group & Visit & Mean \pm s.d. & $p$ \\
\hline \multirow{4}{*}{$\begin{array}{l}\text { Bulbar } \\
\text { redness }\end{array}$} & \multirow[t]{2}{*}{ Intervention } & Baseline & $2.65 \pm 0.87$ & \multirow[t]{2}{*}{0.28} \\
\hline & & Follow-up & $2.30 \pm 0.73$ & \\
\hline & \multirow[t]{2}{*}{ Control } & Baseline & $2.55 \pm 0.61$ & \multirow[t]{2}{*}{0.13} \\
\hline & & Follow-up & $2.9 \pm 0.72$ & \\
\hline \multirow{4}{*}{$\begin{array}{l}\text { Limbal } \\
\text { redness }\end{array}$} & \multirow[t]{2}{*}{ Intervention } & Baseline & $2.4 \pm 0.99$ & \multirow[t]{2}{*}{0.04} \\
\hline & & Follow-up & $1.8 \pm 0.61$ & \\
\hline & \multirow[t]{2}{*}{ Control } & Baseline & $2.30 \pm 0.65$ & \multirow[t]{2}{*}{0.78} \\
\hline & & Follow-up & $2.35 \pm 0.58$ & \\
\hline \multirow{4}{*}{$\begin{array}{l}\text { Palpebral } \\
\text { redness }\end{array}$} & \multirow[t]{2}{*}{ Intervention } & Baseline & $2.60 \pm 0.88$ & \multirow[t]{2}{*}{0.16} \\
\hline & & Follow-up & $2.15 \pm 0.87$ & \\
\hline & \multirow[t]{2}{*}{ Control } & Baseline & $3.1 \pm 0.71$ & \multirow[t]{2}{*}{0.10} \\
\hline & & Follow-up & $2.15 \pm 0.87$ & \\
\hline \multirow{4}{*}{$\begin{array}{l}\text { Palpebral } \\
\text { roughness }\end{array}$} & \multirow[t]{2}{*}{ Intervention } & Baseline & $2.05 \pm 0.88$ & \multirow[t]{2}{*}{0.15} \\
\hline & & Follow-up & $1.70 \pm 0.8$ & \\
\hline & \multirow[t]{2}{*}{ Control } & Baseline & $2.05 \pm 0.9$ & \multirow[t]{2}{*}{0.48} \\
\hline & & Follow-up & $2.05 \pm 0.51$ & \\
\hline \multirow[t]{4}{*}{ MGD } & \multirow[t]{2}{*}{ Intervention } & Baseline & $1.90 \pm 1.07$ & \multirow[t]{2}{*}{0.47} \\
\hline & & Follow-up & $1.70 \pm 0.73$ & \\
\hline & \multirow[t]{2}{*}{ Control } & Baseline & $1.55 \pm 0.82$ & \multirow[t]{2}{*}{0.85} \\
\hline & & Follow-up & $1.5 \pm 0.6$ & \\
\hline \multirow{4}{*}{$\begin{array}{l}\text { Corneal } \\
\text { staining }\end{array}$} & \multirow[t]{2}{*}{ Intervention } & Baseline & $1.90 \pm 1.07$ & \multirow[t]{2}{*}{0.24} \\
\hline & & Follow-up & $1.30 \pm 0.7$ & \\
\hline & \multirow[t]{2}{*}{ Control } & Baseline & $1.50 \pm 0.688$ & \multirow[t]{2}{*}{0.11} \\
\hline & & Follow-up & $1.20 \pm 0.410$ & \\
\hline
\end{tabular}

s.d., standard deviation; MGD, meibomian gland dysfunction.

group $(p=0.38)$. Arshad ${ }^{23}$ reported that with educational intervention, significant change was observed in patients with asthenopia. Motoko et al. ${ }^{24}$ reported that the dry eye symptom score showed a significant decrease in their intervention group. The limited changes in CVS symptoms in the current study may be a result of the participants not following the $20 / 20 / 20$ rule sufficiently during the intervention period; this study was conducted without reminders (e.g. with apps) that could facilitate users more easily following the rule and thus result in a better CVS outcome. Min et al. ${ }^{22}$ reported that there are mobile and desktop applications that can help computer users follow the rule. Recently, Min et al. ${ }^{22}$ proposed an eyewear system for helping users follow the $20 / 20 / 20$ rule that could give better results in future studies. The authors assume that it is difficult for users to direct their eyes at a distance of 20 feet, at intervals of $20 \mathrm{~min}$ and for a period of $20 \mathrm{~s}$. If the time interval for the exercise increases to, say, $40 \mathrm{~s}$ or more, this might make it easier for users to follow the rule.

Interestingly, TBUT in our study exhibited a significant increase after the educational intervention, which was statistically significant $(p=0.005)$. This could be a result of the frequency of blinking during the process of performing the 20/20/20 exercise, which re-wets the cornea, helps prevent dryness and increases the duration of tear break-up time. Reduction in the blink rate during focusing and concentrating on near screens can result in dry eye. Smart eyeglasses developed to stimulate more frequent blinking at intervals of $5 \mathrm{~s}$ have been shown to increase the blink rate, resulting in eliminating the symptoms of CVS. ${ }^{25}$ Although the 20/20/20 rule is popular amongst eye care professionals, there is a paucity of previous studies to assess the clinical and scientific value of the rule. Several researchers ${ }^{15,26,27}$ have investigated the 20/20/20 rule in the management of CVS, near-point stress and also for controlling the progression of myopia, but still there is insufficient scientific evidence.

In this study, ocular surface integrity showed a reduction in limbal redness from Grade 2 to Grade 1 that was statistically significant $(p=0.04)$, but in the control group the limbal redness remained at Grade 2 pre- and post-test ( $p=0.78$ ). In general, there was a slight decrease in signs of dry eye after the education intervention, but this was not statistically significant. Several researchers ${ }^{25,28,29}$ have reported that taking frequent short breaks is considered the most effective method to reduce CVS. These results give us a clue that educational interventions may have an influence on ocular signs and symptoms but not enough to reduce CVS symptoms. The current study has some limitations: the sample size was small, the duration of the intervention was short, and the study was conducted only amongst male participants. Thus, it is recommended that future studies increase the sample size and use a longer period for the intervention, install software on phones and/or computers for break reminders to ensure that the participants accurately follow the 20/20/20 rule and perhaps give supplements like artificial tears where necessary, such as for older patients.

\section{Conclusion}

This study concludes that the educational intervention of the 20/20/20 rule induces significant changes regarding dry eye symptoms and tear film and some limited changes for ocular surface integrity. Thus, the rule has some effect on CVS signs and symptoms but it is not enough to completely eliminate CVS. There was limited evidence suggesting that the educational intervention impacts the reduction of CVS symptoms and associated dry eye signs and symptoms. This pilot study is considered as a foundation stone for larger studies that may provide further evidence towards reducing CVS.

\section{Acknowledgements}

The authors are grateful to the staff and students of the Department of Optometry at Qassim University for their help with the process of data collection. The authors extend their sincere thanks to Mohammed Alharbi and Abdullah Alharbi for their help in data collection. The authors also thank all the students and teachers for their participation in this study.

\section{Competing interests}

The authors declare that they have no financial or personal relationships that may have inappropriately influenced them in writing this article.

\section{Authors' contributions}

W.M.A. was responsible for the project design, data collection and editing of the article. S.H.A. was responsible for the writing and editing of the article. 


\section{Funding information}

This research received no specific grant from any funding agency in the public, commercial or not-for-profit sectors.

\section{Data availability statement}

Data sharing is not applicable to this article.

\section{Disclaimer}

The views and opinions expressed in this article are those of the authors and do not necessarily reflect the official policy or position of any affiliated agency of the authors.

\section{References}

1. Mowatt $L$, Gordon $C$, Santosh $A B$, Jones $T$. Computer vision syndrome and ergonomic practices among undergraduate university students. Int J Clin Pract. 2018;72(1):e13035. https://doi.org/10.1111/ijcp.13035

2. Toe $C$, Gifford $P$, Johnston $V$, Treleaven J. Computer vision symptoms in people with and without neck pain. Appl Ergonom. 2019;80:50-56. https://doi. org/10.1016/j.apergo.2019.04.010

3. Yan Z, Hu L, Chen H, Lu F. Computer vision syndrome: A widely spreading but largely unknown epidemic among computer users. Comp Hum Behav. 2008;24(5):2026-2042. https://doi.org/10.1016/j.chb.2007.09.004

4. Rosenfield M. Computer vision syndrome: A review of ocular causes and potential treatments. Ophthal Physiol Optics. 2011;31(5):502-515. https://doi. org/10.1111/j.1475-1313.2011.00834.x

5. Tauste AF, Ronda-Perez E, Seguí MC. Ocular and visual alterations in computer workers contact lens wearers: Scoping review. Rev Esp Salud Publica. 2014;88(2):203-215. https://doi.org/10.4321/S1135-57272014000200004

6. Akinbinu TR, Mashalla YJ. Impact of computer technology on health: Computer vision syndrome (CVS). Med Pract Rev. 2014;5(3):20-30

7. Smita A, Goel D, Sharma A. Evaluation of the factors which contribute to the ocular complaints in computer workers. J Clin Diagn Res. 2013;7(2):331-335.

8. Kojima T, Ibrahim OM, Wakamatsu T, et al. He impacts of contact lens wear and visual display terminal work on ocular surface and tear function in office workers. Am J Opthalmol. 2011;152(6):933-940. https://doi.org/10.1016/j.ajo.2011.05.025

9. Gowrisankaran S, Sheedy JE. Computer vision syndrome: A review. Work. 2015;52(2):303-314. https://doi.org/10.3233/WOR-152162

10. Bhandeni DJ, Choudhary S, Doshi VG. A community-based study of asthenopia in computer operators. Indian J Opthalmol. 2008;56(1):51-55. https://doi. org/10.4103/0301-4738.37596

11. Chiemeke SC, Akhahowa AE, Ajayi OB. Evaluation of vision-related problems amongst computer users: A case study of University of Benin, Nigeria [homepage on the Internet]. Proceedings of the World Congress on Engineering. Vol. 1, WCE on the Internet]. Proceedings of the World Congress on Engineering. Vol. 1, WCE iaeng.org/publication/WCE2007/WCE2007_pp217-221.pdf
12. Taptagaporn S, Sotoyama M, Saito S, Suzuki T, Saito S. Visual comfort in VDT workstation design. J Hum Ergol. 1995;24(1):84-88

13. Rahman A, Alrasheed SH. The effect of smart educational methods on refractive errors and binocular functions among school-aged children. GCNU J. 2019;12 (2-48):33-42.

14. Bali J, Navin N, Thakur BR. Computer vision syndrome: A study of the knowledge, attitudes and practices in Indian ophthalmologists. Ind J Ophthalmol. 2007;55(4):289. https://doi.org/10.4103/0301-4738.33042

15. Boulet C. The '20/20/20 rule' - When good intentions and axiomatic habit displace best practices. Can J Optometry. 2016;78(4):6. https://doi.org/10.15353/ cjo.78.448

16. Canadian Association of Optometrists. The 20-20-20 rule [homepage on the Internet]. CAO; 2014 [cited 2016 Nov 17]. Available from: https://opto.ca/the-2020-20rule/

17. Del Mar Seguí M, Cabrero-García J, Crespo A, Verdú J, Ronda E. A reliable and valid questionnaire was developed to measure computer vision syndrome at the workplace. J Clin Epidemiol. 2015;68(6):662-673. https://doi.org/10.1016/j. jclinepi.2015.01.015

18. Chalmers RL, Begley CG, Caffery B. Validation of the 5-item Dry Eye Questionnaire (DEQ-5): Discrimination across self-assessed severity and aqueous tear deficient dry eye diagnoses. Cont Lens Anterior Eye. 2010;33(2):55-60. https://doi. org/10.1016/j.clae.2009.12.010

19. Martinez JD, Galor A, Amescua G, et al. Transcultural validation of the 5-item Dry Eye Questionnaire for the Mexican population. International ophthalmology. 2019 Oct 1; 39(10):2313-2324. https://doi.org/10.1007/s10792-018-01068-3

20. Zeev MS, Miller DD, Latkany R. Diagnosis of dry eye disease and emerging technologies. Clin Opthalmol. 2014;8:581-590. https://doi.org/10.2147/OPTH. S45444

21. Artime Ríos EM, Sánchez Lasheras F, Suarez Sánchez A, Iglesias-Rodríguez FJ, Seguí Crespo MD. Prediction of computer vision syndrome in health personnel by means of genetic algorithms and binary regression trees. Sensors. 2019;19(12):2800. https://doi.org/10.3390/s19122800

22. Min C, Lee E, Park S, Kang S. Tiger: Wearable glasses for the 20-20-20 rule to alleviate computer vision syndrome. Proceedings of the 21st International Conference on Human-Computer Interaction with Mobile Devices and Services; Association for Computing Machinery, New York, USA. 2019 Oct 1-4, p. 1-11. https://doi.org/10.1145/3338286.3340117

23. Arshad S, Khan A, Pal DK, Melwani V, Verma S, Sawlani H. Prevalence of asthenopia among computer operators in Central India and effectiveness of educationa intervention. Int J Community Med Public Health. 2019;6(5):2091-2094. https:// doi.org/10.18203/2394-6040.ijcmph20191825

24. Kawashima M, Sano K, Takechi S, Tsubota K. Impact of lifestyle intervention on dry eye disease in office workers: A randomized controlled trial. J Occup Health. 2018;60(4):281-288. https://doi.org/10.1539/joh.2017-0191-OA

25. Chawla A, Lim TC, Shikhare SN, Munk PL, Peh WC. Computer vision syndrome: Darkness under the shadow of light. Can Assoc Radiol J. 2019;70(1):5-9. https:// doi.org/10.1016/j.carj.2018.10.005

26. Barthakur R. Computer vision syndrome. Internet J Med Update. 2013;8(2):1-2.

27. Logaraj M, Madhupriya V, Hegde SK. Computer vision syndrome and associated factors among medical and engineering students in Chennai. Ann Med Health Sci Res. 2014;4(2):179-185. https://doi.org/10.4103/2141-9248.129028

28. Barredo RD, Mahon K. The effects of exercise and rest breaks on musculoskeletal discomfort during computer tasks: An evidence-based perspective. J Phys Therapy Sci. 2007;19(2):151-163. https://doi.org/10.1589/jpts.19.151

29. Reddy SC, Low CK, Lim YP, Low LL, Mardina F, Nursaleha MP. Computer vision syndrome: A study of knowledge and practices in university students. Nepalese Ophthalmol. 2013;5(2):161-168. https://doi.org/10.3126/nepjoph.v5i2.8707 